\title{
The importance of social sources of cigarettes to school students
}

\author{
E Croghan, P Aveyard, C Griffin, K K Cheng
}

Tobacco Control 2003;12:67-73

See end of article for authors' affiliations

.....................

Correspondence to: Emma Croghan,

Behavioural Epidemiology

Research Group,

Department of Public

Health and Epidemiology,

University of Birmingham,

Birmingham B15 2T, UK;

e.croghan@bham.ac.uk

Received 24 May 2002.

Accepted

18 December 2002

\begin{abstract}
Objective: To discover the importance of social sources of tobacco to young people as opposed to commercial sources; to describe the peer market for cigarettes in schools and the consequences for young people of their involvement in it.

Study design: Cross sectional questionnaire survey, one-to-one interviews, and focus groups.

Setting: Seven schools in Birmingham, UK.

Subjects: All students in two randomly selected classes from each school completed the questionnaire, and never smokers, occasional smokers, and regular smokers were interviewed.

Results: Two thirds of occasional smokers and one quarter of regular smokers obtained cigarettes socially, mostly for free. A few smokers regularly bought their cigarettes from others. Among friendship groups, both smokers and non-smokers were involved in the exchange of cigarettes, often for money, which is a common activity. A few young people use the selling of cigarettes to fund their own smoking. Some young people, smokers and non-smokers, are involved in semi-commercial selling of cigarettes. All school students are aware of where to purchase cigarettes from non-friends, which is only used "in emergency" because of the high price. One school had a strong punishment policy for students caught with cigarettes. In this school, more people bought singles from the peer market and the price was higher.

Conclusions: The passing and selling of cigarettes in school is a common activity, which from the young persons perspective, ensures that all share cross counter purchases. A few people are prepared to use the peer market for monetary gain and it appears to be responsive to external conditions. The peer market might mean that efforts to control illegal sales of cigarettes are not as effective as hoped.
\end{abstract}

T he aim of this study is to examine the social market for tobacco among young people. By social market or source, we mean all interpersonal exchange of tobacco, whether for money, for free, or in the anticipation of future reciprocation. We exclude from the social market all direct cross counter purchases made by young people for themselves or purchases from machines, which we term commercial purchases. To study the social market, we conducted a cross sectional questionnaire survey, focus groups, and one-to-one interviews. In our paper we contrast social and commercial purchases.

Most current adult smokers started smoking before the age of 16 years, ${ }^{1}$ implying adolescence is a crucial period determining whether a person will end up addicted to a product that will kill half of its long term users. ${ }^{2}$ However, two thirds of 16 year olds have tried smoking, ${ }^{3}$, while only one third of people at the end of adolescence are smokers, ${ }^{45}$ suggesting that adolescence is a period of experimentation before the habit becomes entrenched.

\section{Policy context}

The UK government target is to reduce smoking prevalence among $11-15$ year olds from $13 \%$ in 1998 to $11 \%$ by 2005 and $9 \%$ by $2010 .^{3}$ This is to be achieved through restricting illegal sales, advertising bans, and price increases. ${ }^{3}$ Other countries, such as the USA and Norway, have used legislative changes to restrict underage cigarette sales as part of their strategy to reduce youth smoking. ${ }^{3}$ In California, underage cross counter purchases more than halved through strict enforcement of laws prohibiting minors from purchasing tobacco. ${ }^{5}$ However, smoking prevalence in young people did not halve. Concurrently, social sources became the main source of cigarettes for young people, where directly purchased commercial sources had been the most important previously. ${ }^{67}$ This implies that a social market expanded to fill the gap left when access to directly bought commercial sources was denied. ${ }^{7}$ More formal evidence on the effect of restricting young people's access to commercial sources comes from controlled studies, summarised in a recent systematic review. ${ }^{8}$ Education of the vendor alone has been ineffective, but there is contradictory evidence that legislation and enforcement can reduce the prevalence of smoking in adolescence. In a commentary on the review, DiFranza argued that studies showing no apparent effect of this approach have not shown that they have restricted access. ${ }^{10}$ If they could not restrict access, they could not influence smoking behaviour. An alternative explanation for the failure of approaches aiming to restrict illegal sales is that a few young people sourced cigarettes and then passed these on to friends and peers, as the Californian experience suggests. Interventions to reduce illegal sales of cigarettes are interventions in the adolescent cigarette market. It is a principle of intervening in the market that we should know how it behaves and how it will react to our intervention. Without knowledge of the peer market, we cannot predict the effects of any intervention with cross counter markets on the "black market" which may exist within schools.

\section{Importance of peer markets}

Aside from helping us to understand the influence of restricting direct commercial sourcing, understanding peer markets is important for other reasons. Peer markets might serve a recruitment function for new smokers, for the financial gain of vendors. Young people typically are given their first cigarettes by peers. ${ }^{7}$ While these first cigarettes are often free, the supplier could become a regular point of access and might start to charge. Profits from peer vending might consolidate the vendor's own habit through increased consumption and drive further recruitment of new smokers. Secondly, access to 
a valued product (cigarettes) might delineate power relations within schools, which could be associated with abuse. Thirdly, because of the interposition of "middle men" between cigarettes original source and the eventual consumer, socially sourced cigarettes could be more expensive. This could mean that those who source cigarettes this way predominantly spend money on cigarettes that is intended for school meals or that could have been spent on other health enhancing behaviours. For these reasons, the operation of peer markets is important in tobacco control and health promotion.

\section{Social sources of tobacco}

Occasional and regular smokers get cigarettes from different sources. Eighty per cent of English youth regular smokers buy their cigarettes from a shop (cross counter purchases), although this has decreased from around 90\% in the mid 1980s. ${ }^{11}$ Seventy four per cent of occasional smokers, however, reported in a national annual UK survey that they most commonly obtained cigarettes from friends, although details of these transactions were not recorded. ${ }^{11}$ Wolfson et al found that $69 \%$ of adolescent smokers had supplied other adolescents with cigarettes in the past week. ${ }^{12}$ The majority of "suppliers" had bought the cigarettes from a retailer. Why would smokers pass on cigarettes that they want to consume and bought with their own money? They must be generous, expecting future reciprocation, or selling these cigarettes. Which of these or other reasons for supplying cigarettes was not recorded. Tencati et al provided some information on this in California. They found that the majority of socially obtained tobacco was given for free, while $46 \%$ asked someone to buy cigarettes on their behalf, $28 \%$ bought from a social source, and $21 \%$ reported stealing tobacco from a social source. ${ }^{7}$

The aims of this study were to describe the extent of social purchasing as opposed to commercial sourcing, the characteristics of and consequences for social purchasers compared to commercial purchasers, and the characteristics of and consequences for the social vendors.

\section{METHODS}

We conducted a cross sectional survey from which individuals representing the three categories of smoking status (nonsmoker, occasional smoker, and regular smoker) were selected to participate in focus groups and interviews.

\section{Ethical approval and consent}

The local research ethics committees approved the study. Parents were asked by letter to reply if they had objections and young people were asked to give positive written consent to participate.

\section{Sampling and data collection}

Data on tobacco acquisition and consumption were obtained from a cross section of students in years 9 and 10 (ages 13-15 years) in schools responsible to the Birmingham local education authority. A priori, we assumed that socioeconomic status would have an important bearing on the way young people's informal tobacco networks operated. Schools were stratified by the percentage of students eligible for free school meals (meaning their parents received financial aid from the state), and one school per stratum selected randomly. Secondly, mixed ability classes were randomly selected from the chosen schools, two year 9 (aged 13-14 years) and two year 10 (aged 14-15 years) classes.

Data collection took place in classrooms under examination conditions, supervised by a trained administrator working to a protocol. We did not leave questionnaires for absentees. The student questionnaires included sociometric items identifying wider peer groups and friendship networks within peer groups, as well as smoking and tobacco acquisition behaviour of the student. It also included items broadly assessing identity, such as type of music liked and types of friends. The questionnaire was developed mainly from previously used adolescent lifestyle questionnaires, ${ }^{13}$ using the standard Office for National Statistics question to assess smoking prevalence ${ }^{14}$ to categorise young people as never smokers, regular smokers (those smoking at least one cigarette per week), and occasional smokers (all others). Questions about social relations (sociometric) were developed by the Medical Research Council Social and Public Health Sciences Unit, and questions about lifestyle, not available from previous questionnaires, were developed through focus groups. The questionnaire was piloted and marginally revised. The test-retest reliability was assessed and found to be good. In the sociometric part of the questionnaire, participants described up to six named friends, and described whether they were in school or outside of school, whether they smoked, and whether and how they obtained tobacco from these friends.

\section{Interviews and focus groups}

Focus groups and one-to-one interviews were carried out in all participating schools to find out more about the responses given by the majority in the questionnaires and to find out more about the availability and knowledge of peer led markets in schools. Participants completing the questionnaire were stratified by school, year, and smoking status (regular, occasional, and never). Three participants were randomly selected from within each school, year, and smoking status to participate in focus groups (42 focus groups in total). Three other participants within each school and year and smoking group were also selected to be interviewed (42 interviews). In each school, a room was sought which was quiet and could be arranged informally, such as a meeting room or conference room. ${ }^{15}$ Potential participants in the focus groups and interviews were informed in advance about the purpose and location of the group and separate consent obtained. The focus groups and interviews were taped and transcribed. Both focus groups and interviews were used as, a priori, we were unsure about the respondents' comfort with talking on tape about smoking and their experiences, and we wanted to find out what groups of students knew and would discuss collectively and what individuals knew about the peer market and their involvement (if any) with it. Interviews lasted around 15 minutes, and focus groups around 30 minutes. Schemas for both interviews and focus groups were developed from the questionnaire responses and included questions about personal knowledge, involvement, and views of peer transactions.

\section{Data analysis}

Quantitative data was generated from the survey. We calculated descriptive statistics for most items. Additionally, we used logistic regression to examine the predictors of purchasing from social sources. Previous data ${ }^{16}$ and this study showed that the dominant influence on whether students bought cigarettes across the counter directly or from peers was whether they were regular or occasional smokers. We therefore adjusted for smoking status and then each characteristic in turn. We intended to use network analysis of friendship groups ${ }^{17}$ to examine the characteristics of vendors in more detail. However, because many friendships were outside of the registration class groups we sampled, this failed, and we have therefore limited quantitative information on the peer vendors. Qualitative data, gathered from interviews and focus groups, were analysed using iterative processes of content analysis, facilitated by the use of NVIVO software, which allows for thematic grouping, coding, and organising. The process of systematically thematically coding the qualitative data using NVIVO software allows identification and coding of the most prominent and persistent themes. Comments, which most clearly illuminated the themes discussed in the 
Table 1 Demographic characteristics of sample by smoking status

\begin{tabular}{|c|c|c|c|c|c|}
\hline & \multicolumn{4}{|c|}{ Smoking status } & \multirow[b]{2}{*}{ Totalt } \\
\hline & Missing* & $\begin{array}{l}\text { Never } \\
\text { smoked* }\end{array}$ & $\begin{array}{l}\text { Occasional } \\
\text { smoker* }\end{array}$ & $\begin{array}{l}\text { Regular } \\
\text { smoker* }\end{array}$ & \\
\hline Total number & $16(2.4)$ & $370(55.9)$ & $214(32.3)$ & $62(9.4)$ & 662 \\
\hline \multicolumn{6}{|l|}{ Ethnicity } \\
\hline White & $10(2.9)$ & $171(49.1)$ & 125 (35.9) & $42(12.1)$ & $348(52.6)$ \\
\hline Mixed & $0(0.0)$ & $21(50.0)$ & $20(47.6)$ & $1(2.4)$ & $42(6.3)$ \\
\hline Asian & $0(0.0)$ & $115(71.4)$ & $33(20.5)$ & $13(8.1)$ & $161(24.3)$ \\
\hline Black & $2(6.7)$ & $18(60.0)$ & $9(30.0)$ & $1(3.3)$ & $30(4.5)$ \\
\hline Other & $0(0.0)$ & $2(66.7)$ & $0(0.0)$ & $1(33.3)$ & $3(0.5)$ \\
\hline Missing & $4(5.1)$ & $43(55.1)$ & $27(34.6)$ & $4(5.1)$ & $78(11.8)$ \\
\hline \multicolumn{6}{|c|}{ Household composition } \\
\hline In care & $0(0.0)$ & $3(20.0)$ & $9(60.0)$ & $3(20.0)$ & $15(2.3)$ \\
\hline 1 parent & $10(7.1)$ & $72(51.4)$ & $43(30.7)$ & $15(10.7)$ & $140(21.1)$ \\
\hline 2 parents & $5(1.0)$ & $285(58.8)$ & $154(31.8)$ & $41(8.5)$ & 485 (73.3) \\
\hline Missing & $1(4.5)$ & $10(45.5)$ & $8(36.4)$ & $3(13.6)$ & $22(3.3)$ \\
\hline \multicolumn{6}{|l|}{ Sex } \\
\hline Male & $9(2.9)$ & $177(56.2)$ & $101(32.1)$ & 28 (8.9) & $315(47.6)$ \\
\hline Female & $6(1.7)$ & $193(55.8)$ & $113(32.7)$ & $34(9.8)$ & $346(52.3)$ \\
\hline Missing & 1 (100.0) & $0(0.0)$ & $0(0.0)$ & $0(0.0)$ & $1(0.2)$ \\
\hline Mean age (SD) & $13.5(0.7)$ & $13.8(0.7)$ & $13.9(0.7)$ & $13.9(0.6)$ & $13.9(0.7)$ \\
\hline
\end{tabular}

Table 2 Usual sources of cigarettes by smoking status

\begin{tabular}{lll}
\hline & \multicolumn{2}{l}{ Smoking status } \\
\cline { 2 - 3 } Usual source of cigarettes & Occasional smoker* & Regular smoker* \\
\hline Commercial source & $33(15.4)$ & $42(67.7)$ \\
Steal from shop & $0(0.0)$ & $1(1.6)$ \\
Buy from shop & $33(15.4)$ & $41(66.1)$ \\
Buys from machine & $0(0.0)$ & $0(0.0)$ \\
Social source & $152(71.0)$ & $16(25.8)$ \\
Buy from student & $12(5.6)$ & $0(0.0)$ \\
Free from student & $48(22.4)$ & $9(14.5)$ \\
Steal from student & $2(0.9)$ & $0(0.0)$ \\
Borrow from student & $7(3.3)$ & $0(0.0)$ \\
Buy from other & $7(3.3)$ & $2(3.2)$ \\
Get free from other & $23(10.7)$ & $4(6.5)$ \\
Steal from other & $1(0.5)$ & $0(0.0)$ \\
Borrow from other & $4(1.9)$ & $0(0.0)$ \\
Social purchase, unknown source & $3(1.4)$ & $0(0.0)$ \\
Social source unspecified & $45(21.0)$ & $1(1.6)$ \\
Unknown & $29(13.6)$ & $4(6.5)$ \\
\hline *Number (\%) of total of that smoking category. & & \\
\hline
\end{tabular}

paper, were therefore chosen to illustrate the points discussed. However, we did not aim only to give typical responses. We have also included some interesting comments which were clearly individual viewpoints, but which added differing perspectives.

\section{RESULTS}

The questionnaires were administered on one occasion in schools and so some students were absent. In total 84 (11.2\%) of students were absent. All those in school when the questionnaire was administered completed the questionnaire $(n=662)$. Three people declined participation in a focus group or interview and were replaced. The characteristics of respondents are shown in table 1.

\section{Access behaviour}

Most $(71.0 \%)$ occasional smokers obtained cigarettes from social sources while most $(67.7 \%)$ regular smokers obtained cigarettes commercially (table 2). For the majority of occasional and regular smokers, social sourcing did not involve the exchange of money, with the majority of occasional smokers obtaining free cigarettes.
Table 3 shows how those who purchased their cigarettes actually bought them. Participants were stratified according to usual method of accessing cigarettes. For those who usually buy cigarettes, we were able to group them according to their place of purchase (a shop, a student in school, someone not in school but a student of a school, or a social acquaintance who was not a student in a school). For each of these categories, we were able to assess the average amount purchased and the average cost at each purchase. We were also able to compare the usual reported sources of money for cigarettes for each group (pocket money, dinner money, and so on). Those buying cigarettes from other students typically purchased singles, whereas those who reported buying cigarettes from someone outside school purchased 10 at a time like those buying from shops. Those buying cigarettes socially as their usual source paid about cost (that is, shop) price.

\section{Characteristics of social sourcers}

The dominant factor associated with social sourcing was smoking status. Table 4 shows the results of logistic regression analysis that adjusted for this, and other factors emerged as associated with social sourcing. The strongest association was 
Table 3 Purchasing information for those who usually buy their cigarettes

\begin{tabular}{|c|c|c|c|c|}
\hline & $\begin{array}{l}\text { Buy from } \\
\text { a shop }\end{array}$ & $\begin{array}{l}\text { Buy from } \\
\text { student }\end{array}$ & $\begin{array}{l}\text { Buy from } \\
\text { other }\end{array}$ & $\begin{array}{l}\text { Social purchase, } \\
\text { unknown source }\end{array}$ \\
\hline Number usually purchased $\dagger$ & $10(4)$ & $1(3)$ & $10(1)$ & $1(2)$ \\
\hline Cost per cigarette $\dagger$ & $19(0)$ & $20(0)$ & $19(0)$ & * \\
\hline \multicolumn{5}{|l|}{ Source of money $\ddagger$} \\
\hline Pocket money & $53(71.6)$ & $6(50.0)$ & $4(44.4)$ & $0(0.0)$ \\
\hline Earnings & $7(9.5)$ & $0(0.0)$ & $2(22.2)$ & $0(0.0)$ \\
\hline Parents & $8(10.8)$ & $2(16.7)$ & $0(0.0)$ & $0(0.0)$ \\
\hline Dinner money & $3(4.1)$ & $2(16.7)$ & $1(11.1)$ & $2(66.7)$ \\
\hline Steal it & $2(2.7)$ & $0(0.0)$ & $0(0.0)$ & $1(33.3)$ \\
\hline No answer & $2(2.7)$ & $2(16.7)$ & $3(33.3)$ & 0 \\
\hline Total & 75 & 12 & 9 & 3 \\
\hline
\end{tabular}

Table 4 Odds ratios for obtaining cigarettes usually by social source compared to retail source*

\begin{tabular}{|c|c|c|}
\hline & OR $(95 \% \mathrm{Cl})$ & $\chi^{2}, \mathrm{df}, \mathrm{p}$ value $\S$ \\
\hline \multicolumn{3}{|l|}{ Smoking status } \\
\hline Occasional smoker ( $v$ regular smoker) & 12.09 (6.08 to 24.05$)$ & $50.4,1,<0.001$ \\
\hline \multicolumn{3}{|l|}{ Sex } \\
\hline Female ( $v$ male) & $0.86(0.46$ to 1.62$)$ & $0.2,1,0.64$ \\
\hline Age (in years) $\dagger$ & 0.88 (0.56 to 1.38 ) & $0.3,1,0.58$ \\
\hline \multicolumn{2}{|l|}{ Ethnicity ( $v$ white) $\ddagger$} & $3.6,3,0.31$ \\
\hline Mixed & $1.42(0.36$ to 5.62$)$ & \\
\hline Asian & $1.62(0.65$ to 4.02$)$ & \\
\hline Black & $0.36(0.08$ to 1.53$)$ & \\
\hline \multicolumn{2}{|l|}{ Feelings about school (vs. neutral) } & $2.3,4,0.68$ \\
\hline Like a lot & $1.36(0.42$ to 4.37$)$ & \\
\hline Like a bit & $1.01(0.46$ to 2.25$)$ & \\
\hline Dislike a bit & $0.52(0.18$ to 1.53$)$ & \\
\hline Dislike a lot & $0.82(0.30$ to 2.27$)$ & \\
\hline Truanting ( $v$ no to truanting) & $0.26(0.11$ to 0.62$)$ & $9.5,1,0.002$ \\
\hline \multicolumn{2}{|l|}{ Friendship identity ( $v$ popular) } & $5.7,4,0.22$ \\
\hline Troublemaker & $0.83(0.37$ to 1.87$)$ & \\
\hline Quiet & $3.94(1.16$ to 13.32$)$ & \\
\hline Loner & $1.25(0.22$ to 7.16$)$ & \\
\hline None of the above & $1.84(0.13$ to 25.82$)$ & \\
\hline \multicolumn{2}{|l|}{$\begin{array}{l}\text { Music preference ( } v \text { everything else) } \\
\text { Hard core }\end{array}$} & $0.5,1,0.48$ \\
\hline Hard core & $0.79(0.41$ to 1.51$)$ & \\
\hline \multicolumn{2}{|l|}{ Smoking pattern ( $v$ alone only) } & $26.4,3,<0.001$ \\
\hline Undefined & 5.58 (1.49 to 20.89$)$ & \\
\hline Alone and with friends & $0.16(0.04$ to 0.60$)$ & \\
\hline With friends only & $0.35(0.16$ to 0.76$)$ & \\
\hline \multicolumn{3}{|c|}{$\begin{array}{l}\text { *All odds ratios (OR) shown are adjusted for smoking status (occasional } v \text { regular) except smoking statu } \\
\text { itself. } \\
\text { †For a } 1 \text { year increase. } \\
\text { fOther deleted. The estimates were unstable. } \\
\S \chi^{2} \text { Wald test from logistic regression equation for inclusion of term. } \\
\mathrm{Cl} \text {, confidence interval. }\end{array}$} \\
\hline
\end{tabular}

with smoking pattern. Those who smoked only alone (the reference category) were much more likely to use a social source than those who smoked also with or only with friends. Those who did not describe with whom they smoked (46\% of occasional smokers and $4 \%$ of regular smokers) were more likely to use social sources to obtain cigarettes. Social sourcing was also more common among particular social types. Those who played truant were much more likely to buy from a commercial source and there was some association with friendship group type, though this was not quite significant overall. Those who described their group as "quiet, friendly, nice, doing well at school" were more likely to obtain cigarettes from social sources, while those who described their group as "troublemaker, rebels" or "sometimes in trouble, don't like school" were slightly more likely to use commercial sourcing rather than those described as "popular, cool, loud, and fun" or "sporty, popular, trendy". The type of music liked by respondents was categorised by three independent young people who all named the two groups of music "punk/rebel" or "square". The former included hip-hop and rap artists such as Eminem and Puff Daddy, while the latter included pop musicians such as Steps and S Club 7. Those liking "punk/rebel" music were slightly but not significantly less likely to purchase from social sources.

\section{Characteristics of social suppliers}

Participants were asked to name up to six friends, their social relation to the participant (in my class, in my year group, in my school, not in my school, left school), and whether they acquired cigarettes in any way from them. The results of this are shown in table 5 . Less than a quarter of participants named any friends outside their school, and the majority of in-school friends were in participants' school year. For in-school friends, whether they were non-smokers or smokers, over half of participants reported the social exchange of cigarettes with these friends. In a quarter to a third of cases, 
Table 5 Cigarette acquisition by participants from named friends

\begin{tabular}{|c|c|c|c|c|c|c|c|c|}
\hline \multirow[b]{3}{*}{ Cigarette acquisition from friend } & \multicolumn{4}{|c|}{ Participant is an occasional smoker } & \multicolumn{4}{|c|}{ Participant is a regular smoker } \\
\hline & \multicolumn{2}{|c|}{ Friend is a non-smoker } & \multicolumn{2}{|c|}{ Friend is a smoker } & \multicolumn{2}{|c|}{ Friend is a non-smoker } & \multicolumn{2}{|c|}{ Friend is a smoker } \\
\hline & $\mathrm{n}$ & $\% *$ & $\mathrm{n}$ & $\% *$ & $\mathrm{n}$ & $\% *$ & $\mathrm{n}$ & $\% *$ \\
\hline \multicolumn{9}{|c|}{ Participants naming $1+$ friend/s in school } \\
\hline Buys from friend & 42 & 23.6 & 24 & 20.9 & 15 & 32.6 & 17 & 34.7 \\
\hline Gets free from friend & 56 & 31.5 & 47 & 40.9 & 11 & 23.9 & 25 & 51.0 \\
\hline Asks friend to buy from a shop & 8 & 4.5 & 10 & 8.7 & 3 & 6.5 & 7 & 14.3 \\
\hline Does not obtain & 93 & 52.2 & 47 & 40.9 & 21 & 45.7 & 7 & 14.3 \\
\hline No friend in this category & 36 & 16.8 & 99 & 46.3 & 16 & 25.8 & 13 & 21.0 \\
\hline \multicolumn{9}{|c|}{ Participants naming $1+$ friend(s) outside school } \\
\hline Buys from friend & 2 & 4.7 & 1 & 3.8 & 0 & 0.0 & 5 & 33.3 \\
\hline Gets free from friend & 6 & 14.0 & 7 & 26.9 & 2 & 33.3 & 6 & 40.0 \\
\hline Asks friend to buy from a shop & 2 & 4.7 & 4 & 15.4 & 1 & 16.7 & 1 & 6.7 \\
\hline Does not obtain & 34 & 79.1 & 15 & 57.7 & 4 & 66.7 & 6 & 40.0 \\
\hline No friend in this category & 171 & 79.9 & 188 & 87.9 & 56 & 90.3 & 47 & 75.8 \\
\hline
\end{tabular}

*Percentage of total number of participants naming friends in this category except for "no friend in this category" which is a percentage of all participants in that smoking category. Categories are not exclusive.

participants reported buying cigarettes from their friends, which was more common when participants were regular smokers than occasional smokers, but did not seem to depend upon the friends' smoking status. However, obtaining cigarettes for free was more common than obtaining them for money. Asking friends to buy cigarettes from shops was an uncommon method of obtaining cigarettes for both occasional and regular smokers. The picture for out of school friends is harder to interpret because few respondents reported such friends. However, the general pattern of frequent social exchange of cigarettes for money or for free with few asking friends to buy cigarettes is supported by the data.

\section{Descriptions of peer market by students}

The interviews and focus groups revealed a wide knowledge among all students of the peer market, its existence, purposes, and methods of working. Perceived purposes were different for different groups of smokers.

For regular smokers, purchases within school often related to feelings of stress and lack of access (not having any cigarettes to hand) to relieve the stress.

"Yes, 'cos if you haven't got any fags [cigarettes] at school and you're pressurised [stressed] they say oh you can buy one and they say something like buy one for a quid [pound], they really skank you [rip you off]." Occasional smoking female, 14 (focus group).

"But if you're really gagging for a fag then you will pay for it." - Regular smoking female, 14 (focus group).

"When you're stressed and stuff it helps."-Occasional smoking female, 13 (focus group).

For occasional smokers, single purchases in school were perceived as more pragmatic and less worrying than purchasing from a shop.

"[lf I bought one when I wanted one] I didn't have to worry about hiding them at home."-Ex-smoker ,13 (interview).

"I buy one, 'cos if I buy 10 then, um, I can't take them back home 'cos I might probably get caught." Occasional smoking male, 14 (interview).

The cost of purchasing tobacco from peers as compared to friends was higher than purchasing from shops. One solution to this was banding together with friends and pooling money to purchase a packet and sharing them.

"We put out like get a box of 10 and one of us puts in, like one pound to begin and then we all put some money in there and we get a box and then like of 10 and we have five each and she takes it back to her house."-Occasional smoking female, 13 (interview).

Prices for single purchases from friends/peers ranged from $20 \mathrm{p}(\$ 0.30 \mathrm{c})$ to $€ 1$ (\$1.50) per single cigarette. Purchases in school from other students were generally of one or two cigarettes at a time, although some adolescents reported purchasing packs of 10 and 20 from social sources.

Vending peers were not necessarily smokers themselves, some were perceived as doing it as an:

". . . easy way to make money. I saw them smoking on the field and buying off mates and stuff and I asked them what they paid and so I went to the onestop and bought 200 with my earnings from the disco and bought them to school . . . I spread it about that I'd got some for 50p each"-Non-smoking male, 14 (interview).

Distinctions were made by young people between supply from "friends" who would supply for free, on a reciprocal basis or at cost, and supply from "non-friends" (peers) who supply for profit and were considered to be exploitative.

"You get skanked buying individually from them (non-friends) because you have to pay 50p for one."-Regular smoking male, 14 (focus group).

"They charge about 20p [a packet of 10 costs around $£ 2.00$, making them cost $20 p$ individually]-they don't really like charge them that much 'cos they're friends anyway."-Occasional smoking female, 14 (focus group).

Generally, peer vendors did not seem to recruit new smokers by touting cigarettes anywhere; however, young people who wanted to smoke knew whom to ask for cigarettes, or what place to be in to be offered cigarettes to buy.

"They come to me ... they come and ask me for one, they say ' $I$ 'll give you $30 p^{\prime \prime \prime}-$ Regular smoking male, 15 (interview). 
"Yeah and um cos I know people who smoke so if they aren't people I really speak to but if I know them a little bit I go and ask them"-Occasional smoking male, 15 (focus group).

Occasionally, peer vendors did tout for sales among smokers or people who hung around with smokers.

"Some people [vendors] flaunt them around school and they'll take one out of their pocket and they [purchasers] go, oh let me buy one off you and it goes on like that." -Non-smoking female, 15 (focus group).

Some participants likened the act of vending by peers to dealing drugs, with vendors identified as "dealers".

"They get them [cigarettes] from older people or older people they have dealers - they have dealers to them ... .

"Like heroin and all that the high grade-he gets it from this marketing place, and he sells it to another one and he gives it to everyone inside.

"What and that happens with smoking, with cigarettes?

"Yeah, sometimes. Cos the dealer gets it for the people."-Occasional smoker, 13 (interview).

\section{Consequences for the social vendor}

Social vendors were often described admiringly.

"Like they buy 20 for $£ 2.50$ in the duty fee zone . . .then you just buy them for $25 p^{\prime \prime}-$ Occasional smoking female, 13 (interview).

Other vendors used the profits from selling cigarettes to fund their own smoking behaviours.

"I buy 10 for $£ 1.80$ or something, sell about four [for $25 p$ each] and that pays for 10 the next day.Occasional smoking male, 14 (interview).

Another vendor talked about stealing four cigarettes from his mother in the morning, using the profits from selling them to buy 10 cigarettes, selling three or four, smoking two or three, and replacing four in his mothers packet each evening.

Some students appear to be making reasonable amounts of money, not just from selling individual cigarettes to peers, but by buying on behalf of younger or more timid students and charging for the service.

"Like some older people will make money off younger students who want cigarettes and then they go and buy them from the shop and they will then want more money off them for going to the shop. And if people want them they will get them all the time for them." -Non-smoking female, 14 (focus group).

Payment in kind to those purchasing on behalf of another also increases the cost to the junior smoker as they lose a proportion of the cigarettes they have bought.

"If they buy you a packet of fags, you crash them one."-Occasional smoking female, 14 (interview).

"Most people will always do it for you [buy on behalf of another] because they know they're going to get some."-Regular smoking female, 13 (focus group).

\section{What this paper adds}

Many adolescents describe obtaining cigarettes from friends or other people rather than buying them from shops, but little is known about these exchanges. If the social exchange of legally bought cigarettes is common, then attempts to prevent smoking in adolescence by restricting illegal sales to underage adolescents would not work.

The social exchange of cigarettes for money and for free is common among friends, regardless of friends' smoking status. A few young people use the selling of cigarettes to raise a substantial income. Buying cigarettes from peers is more common among some social types than others.

One school had a very restrictive policy on smoking in school, and students caught with cigarettes were excluded for a minimum of one week, or until their parents had seen the head teacher. In this school, social sources constituted the usual source of supply for most smokers and the price per cigarette was higher than in other schools, perhaps reflecting the increased risk to peer vendors of being caught with packets of cigarettes.

\section{DISCUSSION}

This study has shown that social exchange of cigarettes, sometimes for money, is common in all schools. For occasional smokers, it provides a convenient form of access. For regular smokers, it is an occasional way to get a cigarette when "it is really needed". Most social vendors appear to be doing this as a simple exchange: cigarettes for money to offset the costs of purchasing across the counter. For a few, both smokers and non-smokers, the social selling of cigarettes provides a substantial income. Some students identified the link between selling of cigarettes and drug pushing, but we found little evidence that selling of cigarettes was a means to recruit smokers or selling or passing on cigarettes was associated with coercive power relationships. Social sourcing of cigarettes is more common among the smokers in some social groups (quiet, doing well at school) than among others (truanting, rebels).

The use of focus groups tended to generate discussion between participants about purposes and methods of transactions, while the interviews tended to lead participants to talk about their own experiences of buying or selling in more depth. This was useful, as it gave an overview of the general opinions about the peer markets as well as specific examples of its uses.

\section{Limitations of the study}

We randomly sampled schools within socioeconomic strata so we believe that the sample included is both unbiased and reasonably socially representative. It may be that young people in this study did not reveal information that has led to a biased picture of the peer market within school. It is known that young people usually provide accurate information about their own smoking status, ${ }^{114}$ however, we asked young people to give their own names and smoking status, and to provide the names, smoking status, and involvement in the peer market of up to six of their closest friends, and to give the names of shops where young people purchased their cigarettes. Nearly always this information was completed. Nearly always the names were plausible, and in some cases the friends named also completed the survey. Only a few shops were named in each school, with many participants actually giving the full addresses. We believe therefore that these answers have face validity. Nevertheless, it remains possible that participants were reluctant to declare their friends' smoking status, which could account for the apparently high involvement of non-smokers in the exchange of cigarettes among friends. 
These data are obtained from students clustered within schools. Statistical tests were based on assumption of independence between students, but this was not true, so that significant associations found in table 4 may not have been truly significant. Additionally, small numbers mean that the point estimates of the percentage buying from friends, for example, could be some way off the true population percentage. However, this was an exploratory study and any associations require confirmation.

\section{Implications of the findings}

The interviews and focus groups revealed that at least some students are involved in fairly large scale (in adolescent terms) commercial selling of cigarettes. Our questionnaire was not designed to reveal this, however, so we cannot estimate how many cigarettes consumed by adolescents come into school this way. It is possible, however, that if tobacco control efforts cut off supply, this route of supply may increase. Those buying cigarettes from "others outside school" bought large quantities at a time.$^{10}$ We speculate that these are potentially illegally imported cigarettes, and that the others outside school from whom young people get cigarettes are working within the adult black market of smuggled, cheap cigarettes. Currently, this is probably a minor route of supply, but it could expand to fill the need for cigarettes created if shops stop selling cigarettes to young people.

The power of vendors on group and individual identity is difficult to assess from this study. There was no evidence that young people involved in the study thought that the vendors were powerful; however, everyone knew them and smokers often spoke of them admiringly. If health promotion should be working to change attitudes and behaviours at the group level, and vendors are holders of "referent power", as French and Raven $^{18}$ put it, then changing these young people's attitudes and behaviour is possibly the key to behaviour and attitude change at a wider level among adolescents.

There is a sense in which young people are "banding together" to obtain cigarettes as a direct challenge to adult opposition. The school with the strong punishment policy for using cigarettes shows that this market is benign for young people, even though they are sometimes monetarily exploited by it. Purchasing, like smoking itself, is part of a repertoire of behaviours that define group and through that individual identity. The social markets provide an important service for occasional and experimental smokers; instead of immediately trying to extinguish these markets, we need to establish methods for preventing smoking and the purchasing of cigarettes being a symbol of groups' and individuals' identities.

\section{ACKNOWLEDGEMENTS}

Emma Croghan is funded by an NHS Research \& Development New Blood Fellowship award, and so was this study. We are grateful to Patrick West and Katrina Turner of the MRC Social and Public Health Sciences Unit, University of Glasgow for help with the questionnaire, and to Mike Pearson, Napier University for help with the sociometric data.
The protocol used to deliver the questionnaire, the questionnaire itself, the piloting process, and the data on the test-retest reliability of the questionnaire are available on the BERG website at www.publichealth.bham.ac.uk/berg/, and also on the Tobacco Control websitewww.tobaccocontrol.com

\section{Authors' affiliations}

E Croghan, P Aveyard, C Griffin, K K Cheng, Behavioural Epidemiology Research Group, Department of Public Health and Epidemiology, University of Birmingham, Birmingham, UK

\section{REFERENCES}

1 US Department of Health and Human Services. Preventing tobacco use among young people. A report of the Surgeon General, 1994. Atlanta, Georgia: Public Health Service, Centers for Disease Control and Prevention, Office on Smoking and Health, 1994. (US Government Printing Office Publication No S/N 017-001-00491-0.1

2 Doll R, Peto R, Wheatley K, et al. Mortality in relation to smoking: 40 years' observations on male British doctors. BM 1994;309:901-11.

3 Secretary of State for Health, Secretary of State for Scotland, Secretary of State for Wales, and Secretary of State for Northern Ireland. Smoking kills. A white paper on tobacco. London: HMSO, 1998.

4 Anon. Statistical bulletin. Statistics on smoking: England, 1976 to 1996. London: HMSO, 1998.

5 Jarvis L. Smoking among secondary school children in 1996: England. London: The Stationery Office, 1997.

6 Ribisl K, Howard-Pitney B, Howard K, et al. Social sources: more California youth now get their cigarettes from social sources than retail sources. 1998.

7 Tencati EM, Ribisl K, Feighery E. Social sources II: who gives cigarettes to underage youth? Implications for interventions. 1998.

8 Stead LF, Lancaster T. Interventions for preventing tobacco sales to minors (Cochrane Review). In: The Cochrane Library, Issue 3. Oxford: Update Software, 2002.

9 Stead LF, Lancaster T. A systematic review of interventions for preventing tobacco sales to minors. Tobacco Control 2000;9:169-76.

10 Difranza JR. Youth access: the baby and the bath water. Tobacco Control 2000;9:120-1.

11 Boreham R, Shaw, A. Smoking, drinking and drug use among young people in England in 2000. London: The Stationery Office, 2001.

12 Wolfson M, Forster JL, Claxton A, et al. Adolescent smokers' provision of tobacco to other adolescents. Am J Public Health 1997;87:649-51.

13 Sherratt E, Macarthur C, Cheng K, et al. West Midlands young people's lifestyle survey 1995-6. Final report. Birmingham: University of Birmingham, 1997.

14 Jarvis L. Smoking among secondary school children in 1996: England. London: The Stationery Office, 1997.

15 Smith JA. Semi-structured interviewing and qualitative analysis. In: Smith $\mathrm{J}$, Harre R, Langenhove L, eds. Rethinking methods in psychology. London: Sage, 1995.

16 Goddard E, Higgins V. Drug use, smoking and drinking among young teenagers in 1999. London: The Stationery Office, 2000.

17 Richards WW. The NEGOPY Network analysis program. British Columbia: Simon Frasier University, 1989

18 French JRP Jr, Raven B. The bases of social power. In: Cartwright D, ed. Studies in social power. New York: Institute for Social Research, 1959. 